\title{
Ultra-wideband Frequency Selective Surface for Communication Applications
}

\author{
Shahid Habib ${ }^{1}$, Ghaffer Iqbal Kiani ${ }^{2}$, Muhammad Fasih Uddin Butt ${ }^{1,3, *}$, Syed Muzahir Abbas ${ }^{4,5}$, \\ Abdulah Jeza Aljohani ${ }^{2}$ and Soon Xin Ng
}

\footnotetext{
${ }^{1}$ Department of Electrical and Computer Engineering, COMSATS University Islamabad, Islamabad, 45550, Pakistan

${ }^{2}$ Department of Electrical and Computer Engineering, King Abdulaziz University, Jeddah, Kingdom of Saudi Arabia

${ }^{3}$ School of Electronics and Computer Science, University of Southampton, Southampton, SO17 1BJ, UK

${ }^{4}$ School of Engineering, Faculty of Science and Engineering, Macquarie University, Sydney, NSW, 2109, Australia

${ }^{5}$ BENELEC, Botany, Sydney, NSW, 2019, Australia

*Corresponding Author: Muhammad Fasih Uddin Butt. Email: fasih@comsats.edu.pk

Received: 08 July 2021; Accepted: 09 August 2021
}

\begin{abstract}
A low-profile ultra-wideband (UWB) band-stop frequency selective surface (FSS) is designed for S-, C-, X-and Ku-bands communication applications. The FSS is constructed by using square and circular loop elements printed on the top and bottom sides of the RO3210 substrate. The FSS has been designed to reduce the electromagnetic interference (EMI) as well as to mitigate the harmful effects of electromagnetic radiation on the human body caused by different radio devices. The dimension and size of the UWB FSS have been reduced to $0.12 \lambda \times 0.12 \lambda$ and $90 \%$, respectively, as compared to the reported literature. The other advantages of the proposed FSS are that it is low profile, it has a simplified geometry and it ensures better angular and polarization stability of up to $85^{\circ}$. The -10 and $-20 \mathrm{~dB}$ bandwidths of the proposed FSS are $146 \%(2.0-13.0 \mathrm{GHz})$ and $80 \%(4.87-11.42 \mathrm{GHz})$, respectively. Theoretical results have been obtained using ANSYS HFSS and verified through measured results.
\end{abstract}

Keywords: Electromagnetic radiation; fractional bandwidth; polarization; transverse electric; transverse magnetic

\section{Introduction}

The study on electromagnetic radiation has received significant attention due to its harmful effects on the performance of radio equipment as well as on the human body [1]. Proliferation in wireless technology has increased electromagnetic radiations caused by different radio devices and transceivers operating on different frequency bands. The electromagnetic interference (EMI) produced by different transmitters has become a significant challenge for the researchers. EMI degrades the performance and operations of wireless and mobile networks. This degradation in wireless systems happens due to electromagnetic induction or electrostatic coupling [2]. Human health has also been affected due to electromagnetic radiations with the proliferation in mobile and wireless technology [3]. Both artificial and natural sources initiate EMI. For example, mobile and satellite networks, ignition systems, lightening and aircrafts etc. produce variable currents

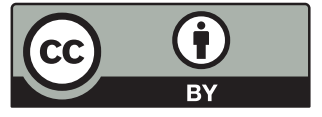

This work is licensed under a Creative Commons Attribution 4.0 International License, which permits unrestricted use, distribution, and reproduction in any medium, provided the original work is properly cited. 
and voltages which degrades the performance of a wireless network. Many solutions have been proposed by different researchers to mitigate the harmful effects of EMI. Researchers have recommended different techniques of electromagnetic shielding for wireless systems operating on very low frequencies [4]. They proposed electromagnetic bandgap structures [5,6], thin metal films [7], metamaterials [8,9] and frequency selective surfaces (FSSs) [10] to resolve the malfunctioning of radio devices due to electromagnetic radiations. However, FSSs have various advantages over these techniques to address the EMI. The periodic structures of FSS are of low cost, lightweight, low profile and easy to design. FSS can be designed to act as a spatial filter, reflectors, polarizer, and absorber to enhance the performance of various telecommunication systems. It can be incorporated into a system to act as a band-stop filter for effective isolation from unwanted signals. The researchers have used different numerical techniques like finite element method (FEM), method of moments (MOM), equivalent circuit model (ECM) and spectral element methods (SEM) to analyze the behavior of electromagnetic (EM) waves through FSSs [11]. FEM has comparable precision to SEM as both have similar number of interpolant points [12]. SEM technique has been shown to achieve high accuracy for a variety of applications [13-18]. In [4], GSM 1800 band has been shielded with $1.3 \mathrm{GHz}$ rejection bandwidth (BW) having signal attenuation of $-20 \mathrm{~dB}$. In [5], the authors have designed a FSS for $\mathrm{Ku}$ band on a flat glass by using crossslot elements for EMI shielding having 0.7 GHz BW with $-10 \mathrm{~dB}$ signal attenuation. In [19], a polarization independent FSS is presented for UWB applications having fractional bandwidth (FBW) of $86.9 \%$. The FSS operates for $0^{\circ}$ and $30^{\circ}$ angle of incidence having BW of $8 \mathrm{GHz}$ with $10 \mathrm{~dB}$ attenuation. In [20], the authors have used cross dipole and circular loop elements to design wideband FSS to achieve shielding effectiveness (SE) for X-and Ka- bands. The angular stability was ensured for $0^{\circ}$ and $45^{\circ}$ incidence having $7.5 \mathrm{GHz}$ bandwidth with $-10 \mathrm{~dB}$ attenuation. A dual layer FSS of $8 \mathrm{GHz}$ bandwidth was presented in [21]. FBW of 114\% was achieved for only normal incidence. In [22] and [23] authors have presented a band-stop FSS with FBW of 48\% for $\mathrm{X}$ - band applications. They investigated angular and polarization stability for normal and oblique angles of incidence. A wideband band-stop FSS of $8 \mathrm{GHz}$ bandwidth with $-10 \mathrm{~dB}$ attenuation was investigated in [24] for normal angle of incidence. FBW of the proposed FSS was achieved $89 \%$. A single layer tri-band FSS for shielding applications was investigated in [25]. The angular stability was ensured for both TE and TM excitations for up to $50^{\circ}$ incidence. The proposed FSS was designed to operate for WiMAX, WLAN and X-band shielding applications. Authors have discussed the advantages of convoluted FSS over the conventional loop elements in [26]. Angular as well as polarization stability of up to $50^{\circ}$ angle of incidence with $120 \% \mathrm{FBW}$ was ensured at $-10 \mathrm{~dB}$ attenuation. In [27] and [28], the impact of low and high permittivity values is investigated, respectively. The band-stop FSS of $2.41 \mathrm{GHz}$, and $1.50 \mathrm{GHz}$ were designed for EMI reduction applications. In [4-10] and [19-30], researchers have proposed unique designs to mitigate the effects of EMI and to improve isolation in UWB and 5G applications [31-33]. However, some important parameters of FSSs such as thickness, bandwidth, fractional bandwidth, periodicity, signal attenuation, angular stability for horizontal and vertical polarizations schemes need to be further investigated to enhance the performance of the FSS for EMI reduction applications. This paper presents a low profile, compact and lightweight dual-layer UWB FSS for S-, C-, X- and $\mathrm{Ku}$ bands applications. Based on the following novel characteristics, the proposed FSS is appropriate to enhance the performance of different radio equipment by reducing EMI: 
- Bandwidth of the proposed FSS is of 11 and $6.55 \mathrm{GHz}$ with an attenuation of -10 and $-20 \mathrm{~dB}$ ranging from $2-13 \mathrm{GHz}$ and $4.87-11.42 \mathrm{GHz}$, respectively.

- FBW of the proposed FSS at -10 and $-20 \mathrm{~dB}$ levels are $146 \%$ and $80 \%$, respectively.

- Angular and polarization stability of UWB FSS is achieved of up to $85^{\circ}$ incidence as the gap between the two adjacent elements has been reduced to $\lambda / 8$ at center frequency.

- To make it low-profile and lightweight, dimension and size of the FSS has been reduced to $0.12 \lambda$ and $94 \%$ at the center frequency, respectively.

- The thickness of the FSS has been reduced to $\lambda / 31$ as compared to the thickness of multilayer FSS which is $\lambda / 4$, proposed in [21].

\section{Design and Results}

Figs. 1a-1c show the 3D view, dimensions, and layout of the unit cell of UWB FSS. The length (L) and width (W) of the unit cell is $4.98 \mathrm{~mm}$ along $\mathrm{x}$ - and y-axis. The dielectric permittivity $(\epsilon)$ of the substrate is 10 , whereas loss tangent is 0.003 . For theoretical analysis, square and circular elements are modeled as a perfect conductor. The thickness of each element is 0.035 $\mathrm{mm}$. The length (L) and the outer radius (R) of square-loop and circular-loop FSS are calculated using the below equations.

$$
\begin{aligned}
& L \approx \frac{c}{4 \times f_{0} \times \sqrt{(\varepsilon+1) / 2}} \\
& R \approx \frac{c}{2 \times \pi \times f_{0} \times \sqrt{(\varepsilon+1) / 2}}
\end{aligned}
$$

In the above equations, the speed of light is represented by $c$, the dielectric permittivity by $\epsilon$, operating frequency by $f_{0}$, and $\pi=3.14$. To understand the conductive and inductive behavior of the proposed UWB FSS, equivalent circuit model (ECM) of UWB FSS is presented in Fig. 2. The values of lumped elements are calculated by using the numerical analysis of ECM presented in $[21,34,35]$. ANSYS HFSS [36] has been used for modeling and simulation purposes. The experimental setup to validate the simulation results is shown in Fig. 3. The unit cell is excited by a plane wave through floquet ports using master-slave boundaries. To achieve the ultra-wideband band-stop characteristic of the proposed FSS, modified square-loop FSS (MSLFSS) and circular-loop FSS elements are printed on the top and bottom surfaces of RO3210 substrate. By coupling both the elements on the same substrate, lower $\left(f_{l}\right)$ and higher $\left(f_{h}\right)$ resonance frequencies are achieved, respectively as shown in Fig. 4. Firstly, MSLFSS was designed and simulated. The resonance frequency and transmission coefficient of MSLFSS are $6.1 \mathrm{GHz}$, and $65.42 \mathrm{~dB}$, respectively. Secondly, circular-loop was designed and simulated. For circular-loop, resonance frequency and transmission coefficient are $8.07 \mathrm{GHz}$, and $57.96 \mathrm{~dB}$, respectively. The bandwidth of the MSLFSS and circular-loop is 7.60 and $5.47 \mathrm{GHz}$ with $-10 \mathrm{~dB}$ attenuation, respectively, as shown in Fig. 4. Finally, for the proposed UWB FSS, two resonance frequencies are observed as shown in Fig. 4. The $f_{1}$ and $f_{h}$ resonance frequencies of UWB FSS are 5.3 and $8.37 \mathrm{GHz}$ with transmission coefficients of -55.13 and $-71.19 \mathrm{~dB}$, respectively. A bandwidth of $11 \mathrm{GHz}$ ranging from 2 to $13 \mathrm{GHz}$ is achieved with $-10 \mathrm{~dB}$ attenuation. When MSLFSS and circular-loop are loaded together on the opposite surfaces of the substrate, resonance frequencies of UWB FSS are moved across from 6.1 to $5.3 \mathrm{GHz}$ and $8.07 \mathrm{GHz}$ to $8.37 \mathrm{GHz}$ due to the mutual coupling effect, as shown in Fig. 4. The simulated results of ECM are also presented in Fig. 4 which are also validating the theoretical results of UWB FSS. To endorse the simulated results, a prototype of the proposed FSS having $420 \times 380$ cells was fabricated using RO3210. 
Network analyzer PNA-X N5242A [37], with two H-1498 series horn antennas [38] were used to measure the experimental results. The operating bandwidth of network analyzer and horn antenna is $10.0-26.5 \mathrm{GHz}$ and $2.0-18.0 \mathrm{GHz}$, respectively. The $3 \mathrm{~dB}$ beamwidth of the horn antennas are $80^{\circ}$ and $50^{\circ}$ in $\mathrm{E}$ - and $\mathrm{H}$-plane, respectively. To limit the transmission of S-, $\mathrm{C}-$, $\mathrm{X}$ - and Ka-bands signals, a screen made from aluminum is assembled with the stand. The transmitting (Tx) antenna and receiving ( $\mathrm{Rx}$ ) antenna is placed on opposite sides of the rotating stand. Before placing the prototype in the stand for measurement, it has been ensured that both the antennas are perpendicular to each other with transparent line-of-sight (LOS). Experimental setup is calibrated through open window and propagation loss is measured. The propagation loss is subtracted later from the measured values of FSS to remove the effect of attenuated signals. The distance between the two antennas is $300 \mathrm{~mm}$ which is calculated using the following equation.

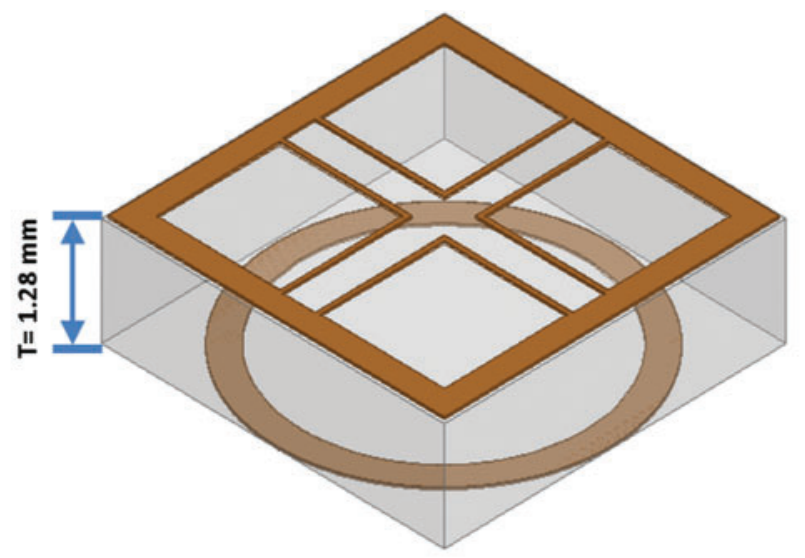

(a)

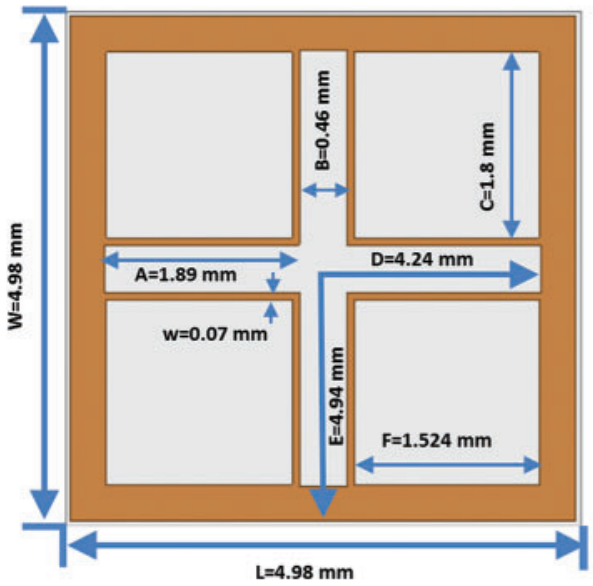

(b)

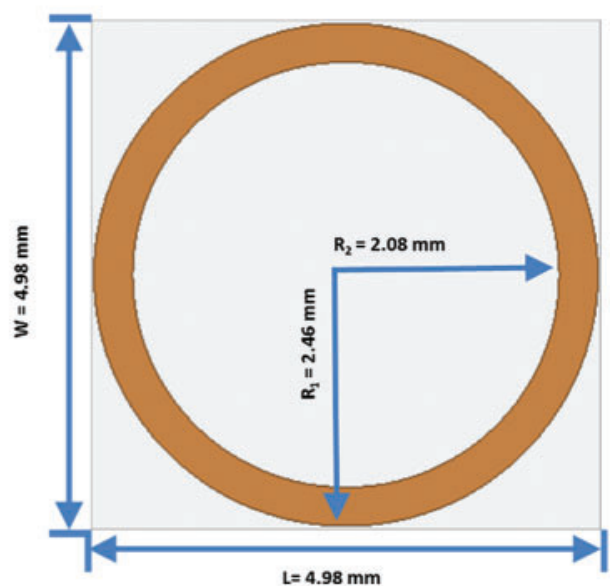

(c)

Figure 1: Geometry of dual layer UWB FSS, (a) 3D-view of UWB FSS unit cell, (b) upper view of square loop element, (c) bottom view of circular loop element 


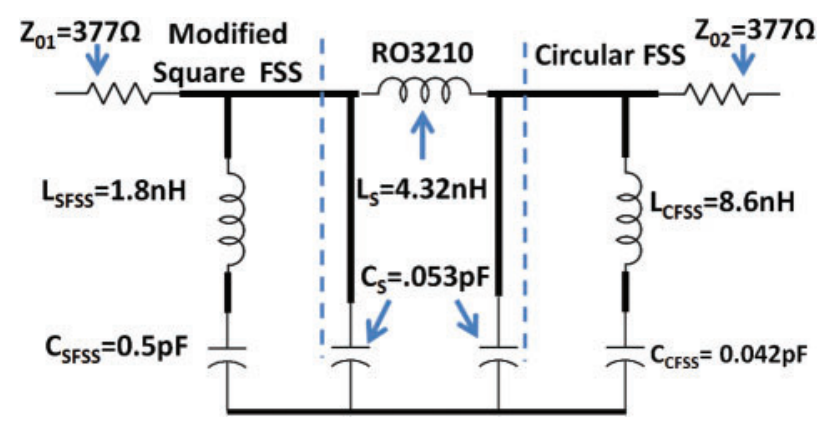

Figure 2: Equivalent circuit model (ECM) of the proposed UWB FSS

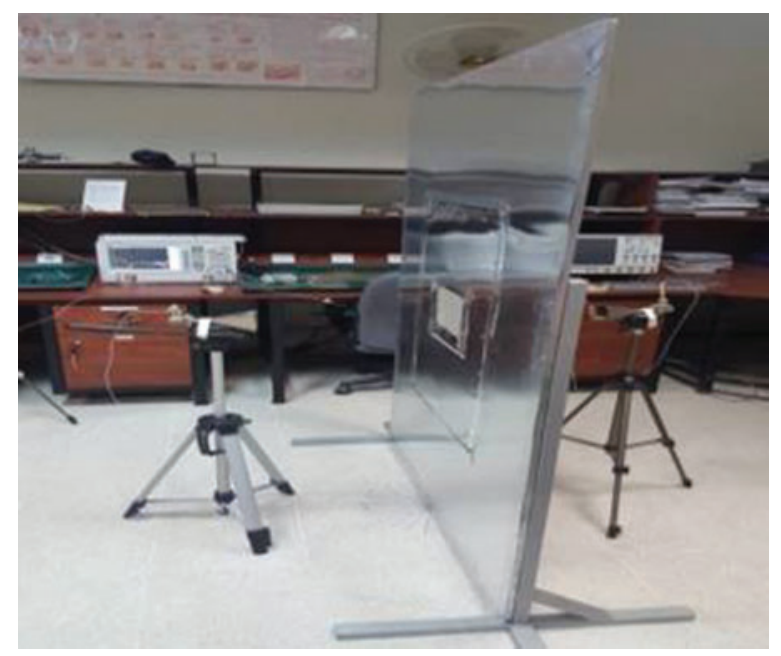

Figure 3: Experimental setup to measure the transmission response of the proposed FSS

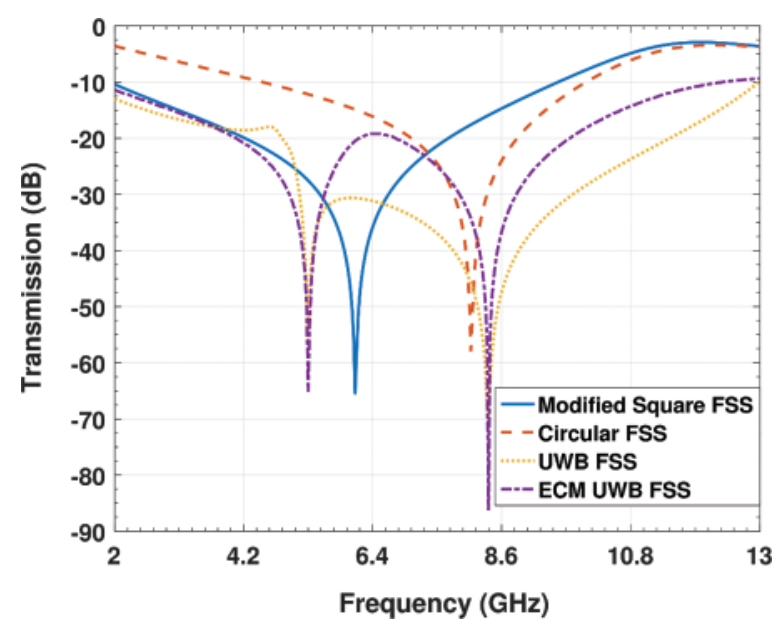

Figure 4: Simulation transmission results of MSLFSS, circular-loop, UWB FSS and ECM UWB FSS for $0^{\circ}$ incidence

$d \geq \frac{2 D^{2}}{\lambda}$ 
where $\mathrm{d}, \lambda$ and $\mathrm{D}$ are representing the far-field distance between the Tx and $\mathrm{Rx}$ antennas, the wavelength, and the maximum dimension of horn antennas, respectively. The simulation and measured transmission coefficients of UWB FSS are presented in Figs. 5a and 5b. Tab. 1 summarizes $-10 \mathrm{~dB} B W$ of the proposed FSS for $f_{1}$ and $f_{h}$ resonance frequencies for transmission coefficients for both $0^{\circ}$ and $85^{\circ}$ angles of incidence. It is quite clear that there is a great similarity in theoretical and experimental results as shown in Figs. 5a and 5b. Fig. 6 shows the physics of UWB FSS when a unit cell is excited by a plane wave at $7.5 \mathrm{GHz}$. Higher current density can be observed on the surface of MSLFSS and circular-loop element along z+-axis at $7.5 \mathrm{GHz}$. This phenomenon is also demonstrating the reflection or band-stop characteristics of the UWB FSS.

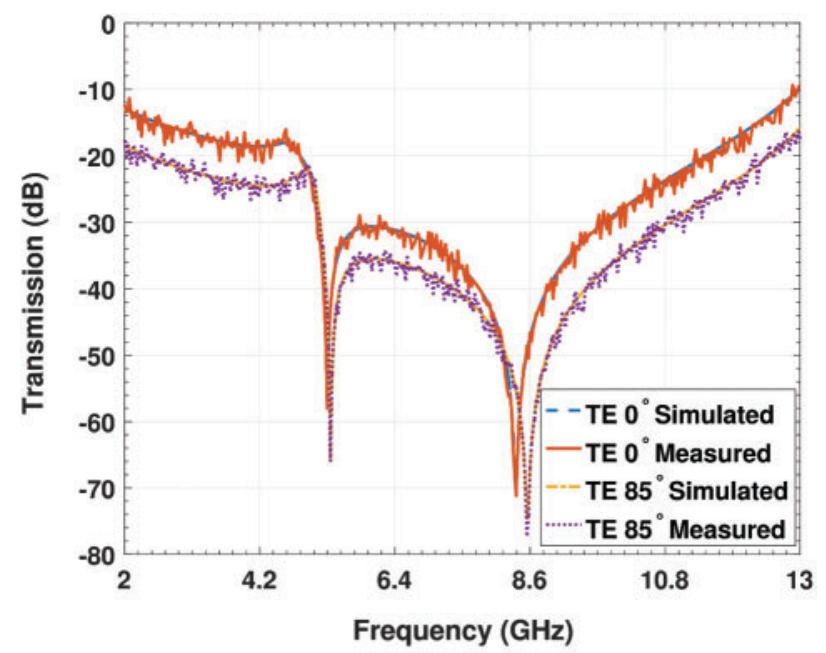

(a)

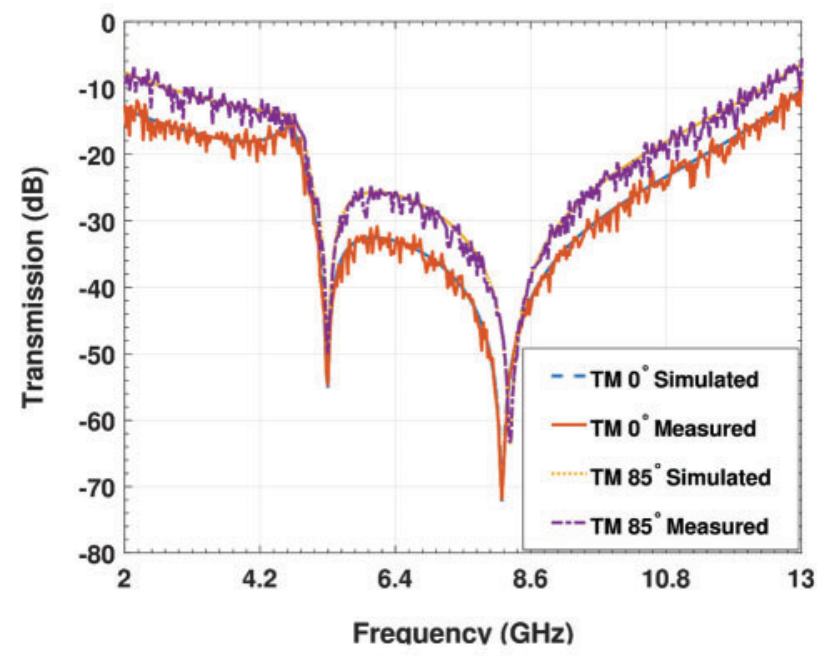

(b)

Figure 5: (a) Simulated and experimental results of TE polarization. (b) Simulated and experimental results of TM polarization 
Table 1: Transmission characteristics of UWB FSS at lower $\left(f_{1}\right)$ and higher $\left(f_{h}\right)$ resonance frequencies

\begin{tabular}{llllllllll}
\hline $\begin{array}{l}\text { Polarization } \\
\text { \& angle of } \\
\text { incidence }\end{array}$ & $\begin{array}{l}\text { Bandwidth } \\
(\mathrm{GHz})\end{array}$ & $\begin{array}{l}\text { Simulated } \\
\mathrm{f}_{1}(\mathrm{GHz})\end{array}$ & $\begin{array}{l}\text { Simulated } \\
\mathrm{S}_{12}(\mathrm{~dB})\end{array}$ & $\begin{array}{l}\text { Measured } \mathrm{f}_{1} \\
(\mathrm{~dB})\end{array}$ & $\begin{array}{l}\text { Measured } \\
\mathrm{S}_{12}(\mathrm{GHz})\end{array}$ & $\begin{array}{l}\text { Simulated } \\
\mathrm{f}_{\mathrm{h}}(\mathrm{GHz})\end{array}$ & $\begin{array}{l}\text { Simulated } \\
\mathrm{S}_{12}(\mathrm{~dB})\end{array}$ & $\begin{array}{l}\text { Measured } \\
\mathrm{f}_{\mathrm{h}}(\mathrm{GHz})\end{array}$ & $\begin{array}{l}\text { Measured } \\
\mathrm{S}_{12}(\mathrm{~dB})\end{array}$ \\
\hline TE $0^{\circ}$ & 11.00 & 5.30 & -55.13 & 5.32 & -58.04 & 8.37 & -72.26 & 8.38 & -69.95 \\
TE $85^{\circ}$ & 11.00 & 5.32 & -49.63 & 5.35 & -66.09 & 8.53 & -74.82 & 58.55 & -77.13 \\
TM $0^{\circ}$ & 11.00 & 5.30 & -55.13 & 5.32 & -58.04 & 8.37 & -72.26 & 8.38 & -69.95 \\
TM $85^{\circ}$ & 9.78 & 5.30 & -52.70 & 5.31 & -54.66 & 8.27 & -63.55 & 8.25 & -63.34 \\
\hline
\end{tabular}

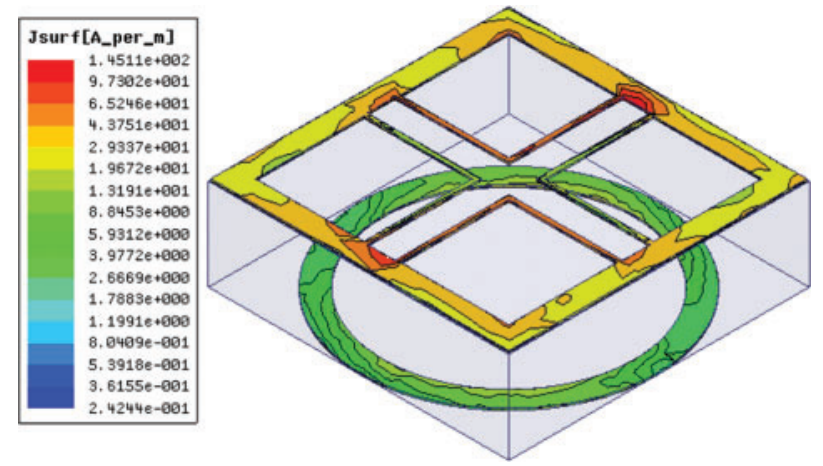

Figure 6: Distribution of electric current on the surface of square and circular element at center frequency $7.5 \mathrm{GHz}$

\section{Performance Analysis of UWB FSS}

The performance of the UWB FSS has been analyzed based on various parameters such as SE, BW, FBW, dimensions, size, thickness, angular and polarization stability. Tab. 2 illustrates various important aspects of band-stop FSSs which have been explored by different researchers. In Refs. [20-23,27,28,39-46] BWs of 7.5, 8, 4, 4, 2.41, 1.63, 9, 7.53, 10.75, 3.64, 6.11, 10.2, 0.6 and $9.9 \mathrm{GHz}$ with $-10 \mathrm{~dB}$ attenuations having FBW of $73.17 \%, 116 \%, 48 \%, 48 \%, 28.57 \%, 16.35 \%$, $98.68 \%, 101.53 \%, 136.42 \%, 67.9 \%, 121.59 \%, 124.39 \%, 50 \%$ and $120 \%$, respectively have been achieved. However, these BWs and FBWs were achieved by compromising on SE, dimensions, thickness, angular as well as polarization stability, as depicted in Tab. 2.

Table 2: Comparison of various FSS reported in the literature at $-10 \mathrm{~dB}$

\begin{tabular}{lllllll}
\hline Ref. & $\begin{array}{l}\text { Bandwidth } \\
(\mathrm{GHz})\end{array}$ & $\begin{array}{l}\text { Fractional } \\
\text { Bandwidth } \\
(\%)\end{array}$ & $\begin{array}{l}\text { Angular } \\
\text { Stability } \\
(\mathrm{deg})\end{array}$ & $\begin{array}{l}\text { Thickness } \\
(\mathrm{mm})\end{array}$ & $\begin{array}{l}\text { Periodicity } \\
(\mathrm{mm})\end{array}$ & $\begin{array}{l}\text { Size } \\
\left(\mathrm{mm}^{2}\right)\end{array}$ \\
\hline$[20]$ & 7.5 & 73.17 & 45 & 3.2 & 12.0 & 144.0 \\
{$[21]$} & 8.0 & 116.0 & 0 & 1.8 & 16.0 & 256.0 \\
{$[22]$} & 4.0 & 48.0 & 45 & 1.6 & 7.5 & 56.25 \\
{$[23]$} & 4.0 & 48.0 & 60 & 0.127 & 6.5 & 42.25 \\
{$[27]$} & 2.41 & 28.57 & 0 & 7.75 & 10.0 & 100.0 \\
\hline
\end{tabular}


Table 2: Comparison of various FSS reported in the literature at $-10 \mathrm{~dB}$.

\begin{tabular}{lllllll}
\hline Ref. & $\begin{array}{l}\text { Bandwidth } \\
(\mathrm{GHz})\end{array}$ & $\begin{array}{l}\text { Fractional } \\
\text { Bandwidth } \\
(\%)\end{array}$ & $\begin{array}{l}\text { Angular } \\
\text { Stability } \\
(\mathrm{deg})\end{array}$ & $\begin{array}{l}\text { Thickness } \\
(\mathrm{mm})\end{array}$ & $\begin{array}{l}\text { Periodicity } \\
(\mathrm{mm})\end{array}$ & $\begin{array}{l}\text { Size } \\
\left(\mathrm{mm}^{2}\right)\end{array}$ \\
\hline$[28]$ & 1.63 & 16.35 & 75 & 2.0 & 3.0 & 9.0 \\
{$[39]$} & 7.53 & 98.68 & 45 & 1.6 & 14.0 & 156.0 \\
{$[40]$} & 9.9 & 101.53 & 60 & 1.6 & 11.5 & 132.25 \\
{$[41]$} & 10.75 & 136.42 & 80 & 1.6 & 8.0 & 64.0 \\
{$[42]$} & 3.64 & 67.9 & 45 & 2.1 & 15.0 & 225.0 \\
{$[43]$} & 6.11 & 121.59 & 30 & 1.6 & 10.32 & 106.53 \\
{$[44]$} & 10.2 & 124.39 & 45 & 1.6 & 10.0 & 100.0 \\
{$[45]$} & 0.6 & 50.0 & 60 & 0.8 & 7.0 & 49.0 \\
{$[46]$} & 9.0 & 120.0 & 80 & 1.524 & 6.0 & 36.0 \\
Proposed & 11.0 & 146.66 & 85 & 1.28 & 4.98 & 24.8 \\
\hline
\end{tabular}

In this research, the efficiency of the FSS has been improved by enhancing the performance of various parameters of the UWB FSS as compared to the designs presented by various authors for communication applications.

For both TE and TM mode, BW has been extended to $11 \mathrm{GHz}$ with FBW of $146 \%$, angular stability is improved to $85^{\circ}$, SE of FSS has been enhanced to more than $10 \mathrm{~dB}$, and better resonance stability has been achieved for UWB FSS as shown in Tab. 2. The miniaturization in dimension and size of unit cell has been achieved by selecting MSLFSS and circular-loop elements and employing them on the top and bottom surfaces of the substrate. The size of UWB FSS is reduced about $82.77 \%, 90.31 \%, 57.76 \%, 41.30 \%, 75.19 \%, 84.34 \%, 81.24 \%, 61.24 \%, 88.97 \%$, $76.69 \%, 75.19 \%, 49.38 \%$ and $31.11 \%$ in comparison to [20-23,27,39-46], respectively. Stability of UWB has been investigated and ensured for TE and TM modes up to $85^{\circ}$ by reducing the gap up to $\lambda / 8$ between the adjacent elements and verified through simulated and experimental results. To achieve the flatness in the transmission curve, dielectric slab of RO3210 was placed between the square loop and circular-loop elements as recommended in [10]. The periodicity of FSS unit cell along $\mathrm{x}$-axis and $\mathrm{y}$-axis is $0.12 \lambda$ at $\mathrm{f}_{\mathrm{c}}$ which is $2.44,3.21,1.5,1.3,2,2.81,2.3,1.6,3.01,2.07$, 2.27, 1.40 and 1.20 times smaller than the periodicity presented in [20-23,27,39-46], respectively. At $7.5 \mathrm{GHz}$ density of RO3210 is $\lambda / 31$ which is lesser than $\lambda / 4$ as established in [21] for multilayer FSS. The grating lobe or scattering was not experienced because of smaller gap between the adjacent elements making the UWB FSS more consistent for TE and TM excitations at normal as well as oblique incidence. It has been experienced that UWB FSS has achieved angular stability for higher oblique angular incidence. At $0^{\circ}$ UWB FSS possesses identical frequency response for TE and TM plane waves due to symmetrical design. However, it is observed that transmission characteristics of UWB FSS are changed for TE and TM excitations as the oblique incidence is increased. The bandwidth of UWB FSS for TE polarized wave is increased and vice versa for TM mode as oblique angular incidence is increased. This variation in the BW happened because the wave impedance of a plane wave is changed for TE and TM due to increase in oblique incidence as investigated by [47-52]. The quality factor is directly proportional to the change in the wave impedance. The wave impedance decreases for TE mode and increases for TM mode as the oblique angular incidence increases. Smaller quality factor for TE mode increases the BW of UWB FSS and larger quality factor leads to smaller BW for TM excitation. 


\section{Conclusion}

A lightweight and low profile UWB FSS is designed and validated up to $85^{\circ}$ through theoretical and measured results. For S-, C-, X- and Ku-bands a bandwidth of $11 \mathrm{GHz}$ is ensured at $10 \mathrm{~dB}$ signal attenuation for TE and TM excitations. The proposed FSS with $146 \%$ fractional bandwidth is suitable for various applications such as EMI reduction and suppression in radio and aerospace networks. It can also be used to mitigate the effects of electromagnetic waves on the human body and to enhance the radiation characteristics of UWB antennas.

Funding Statement: The work was supported by King Abdulaziz University, Jeddah, Kingdom of Saudi Arabia. M. F. U. Butt would like to gratefully acknowledge the Higher Education Commission (HEC), Government of Pakistan's financial support through its Post-Doctoral Fellowship Program (PDFP) Grant.

Conflicts of Interest: The authors declare that they have no conflicts of interest to report regarding the present study.

\section{References}

[1] N. Lawrentschuk and D. M. Bolton, "Mobile phone interference with medical equipment and its clinical relevance: A systematic review," Medical Journal of Australia, vol. 181, no. 3, pp. 145-149, 2004.

[2] A. I. Zverev, Handbook of Filter Synthesis. New York, USA: Wiley, 1967.

[3] R. S. A. Larik, G. A. Mallah, M. M. A. Talpur, A. K. Suhag and F. A. Larik, "Effects of wireless devices on human body," Journal of Computer Science \& Systems Biology, vol. 9, no. 4, pp. 119-124, 2016.

[4] R. Sivasamy, M. Kanagasabai, S. Baisakhiya, R. Natarajan, J. K. Pakkathillam et al., "A novel shield for GSM, $1800 \mathrm{MHz}$ band using frequency selective surface," Progress in Electromagnetics Research Letters, vol. 38, pp. 193-199, 2013.

[5] H. Chen and Y. Chou, "An EMI shielding FSS for Ku-band applications," in IEEE Int. Sym. on Antennas and Propagation, Chicago, IL, USA, pp. 1-2, 2012.

[6] N. Engheta and R. W. Ziolkowski, Electromagnetic Metamaterials: Physics and Engineering Explorations. New York, NY: Wiley-IEEE Press, 2006.

[7] S. Celozzi, R. Araneo and G. Lovat, Electromagnetic Shielding. Hobokenm, NJ: Wiley-IEEE Press, 2008.

[8] D. Seetharamdoo, M. Berbineau, A. Tarot and K. Mahdjoubi, "Evaluating the potential shielding properties of periodic metamaterial slabs," in Int. Sym. on Electromagnetic Compatibility-EMC Europe, Athens, Greece, pp. 1-4, 2009.

[9] D. Sievenpiper, L. Zhang, R. F. J. Broas, N. G. Alexopolous and E. Yablonovitch, "High-impedance electromagnetic surfaces with a forbidden frequency band," IEEE Transactions on Microwave Theory and Techniques, vol. 47, no. 11, pp. 2059-2074, 1999.

[10] B. A. Munk, Frequency Selective Surfaces: Theory and Design. New York, USA: John Wiley \& Sons, 2005.

[11] R. S. Anwar, M. Lingfeng and N. Huansheng, "Frequency selective surfaces: A review," Applied Sciences, vol. 8, no. 9, pp. 1689, 2018.

[12] Y. Liu, J. Teng, H. Lan, X. Si and X. Ma, "A comparative study of finite element and spectral element methods in seismic wavefield modeling," Geophysics, vol. 79, no. 2, pp. 91-104, 2014.

[13] S. Alabed, I. Mahariq, M. Salman and M. Kuzuoğlu, "A novel beamforming emulating photonic nanojets for wireless relay networks," Computers Materials \& Continua, vol. 69, no. 1, pp. 575-588, 2021.

[14] I. Mahariq, H. Kurt and M. Kuzuoğlu, "Questioning degree of accuracy offered by the spectral element method in computational electromagnetics," Applied Computational Electromagnetics Society Journal, vol. 30, no. 7, pp. 698-705, 2015. 
[15] I. Mahariq, I. H. Giden, H. Kurt, O. V. Minin and I. V. Minin, "Strong electromagnetic field localization near the surface of hemicylindrical particles," Optical and Quantum Electronics, vol. 50, no. 11, pp. 1-8, 2018.

[16] I. Mahariq, M. Kuzuoğlu, I. H. Tarman and H. Kurt, "Photonic nanojet analysis by spectral element method," IEEE Photonics Journal, vol. 6, no. 5, pp. 1-14, 2014.

[17] I. Mahariq, M. Kuzuoğlu and I. H. Tarman, "On the attenuation of the perfectly matched layer in electromagnetic scattering problems with the spectral element method," Applied Computational Electromagnetics Society Journal, vol. 29, no. 9, pp. 701-710, 2014.

[18] I. Mahariq, I. Arpaci and M. Kuzuoğlu, "Analysis of scattering from perfect electric conducting cylinders by spectral element method," in Computational Electromagnetics International Workshop (CEM), Izmir, Turkey, pp. 1-2, 2015

[19] F. C. G. da Silva Segundo, A. L. P. S. Campos and E. C. Braz, "Wideband frequency selective surface for angular and polarization independent operation," Microwave and Optical Technology Letters, vol. 57, no. 1, pp. 216-219, 2015.

[20] I. S. Syed, Y. Ranga, L. Matekovits, K. P. Esselle and S. Hay, "A single layer frequency-selective surface for ultrawideband electromagnetic shielding," IEEE Transactions on Electromagnetic Compatibility, vol. 56, no. 6, pp. 1404-1411, 2014.

[21] N. Kushwaha, R. Kumar, R. R. Krishna and T. Oli, "Design and analysis of new compact UWB frequency selective surface and its equivalent circuit," Progress in Electromagnetics Research C, vol. 46, pp. 31-39, 2014.

[22] W. Y. Yong, S. K. Abdul Rahim, M. Himdi, F. C. Seman, D. L. Suong et al., "Flexible convoluted ring shaped FSS for X-band screening application," IEEE Access, vol. 6, pp. 11657-11665, 2018.

[23] M. Nauman, R. Saleem, A. K. Rashid and M. F. Shafique, "A miniaturized flexible frequency selective surface for X-band applications," IEEE Transactions on Electromagnetic Compatibility, vol. 58, no. 2, pp. 419-428, 2016.

[24] N. Liu, X. Sheng, C. Zhang, J. Fan and D. Guo, "A design method for synthesizing wideband bandstop FSS via its equivalent circuit model," IEEE Antennas and Wireless Propagation Letters, vol. 16, pp. 2721-2725, 2017.

[25] M. Bashiri, C. Ghobadi, J. Nourinia and M. Majidzadeh, "WiMAX, WLAN, and X-Band filtering mechanism: Simple-structured triple-band frequency selective surface," IEEE Antennas and Wireless Propagation Letters, vol. 16, pp. 3245-3248, 2017.

[26] E. A. Parker and A. N. A. El Sheikh, "Convoluted array elements and reduced size unit cells for frequency-selective surfaces," IEE Proceedings Part H-Microwaves, Antennas and Propagation, vol. 138, no. 1, pp. 19-22, 1991.

[27] F. Yu, J. Wang, J. Wang, H. Ma, H. Du et al., "Reflective frequency selective surface based on lowpermittivity dielectric metamaterials," Applied Physics Letters, vol. 107, no. 21, pp. 211906-211910, 2015.

[28] L. Li, J. Wang, J. Wang, H. Du, H. Huang et al., "All-dielectric metamaterial frequency selective surfaces based on high-permittivity ceramic resonators," Applied Physics Letters, vol. 106, no. 21, pp. 212904-221909, 2015.

[29] H. Zahra, S. M. Abbas, R. M. Hashmi, L. Matekovits and K. P. Esselle, "Bending analysis of switchable frequency selective surface based on flexible composite substrate," in IEEE Int. Sym. on Antennas and Propagation and USNC-URSI Radio Science Meeting, Atlanta, GA, US, pp. 2033-2034, 2019.

[30] H. Zahra, S. M. Abbas, M. F. Shafique and K. P. Esselle, "A switchable FSS based on modified Jerusalem-cross unit cell with extended top loading," in Int. Sym. on Antennas and Propagation, Hobart, TAS, Australia, pp. 1-2, 2015.

[31] M. Qu, Y. Feng, J. Su and S. M. A. Shah, "Design of a single-layer frequency selective surface for 5G shielding," IEEE Microwave and Wireless Components Letters, vol. 31, no. 3, pp. 249-252, 2021.

[32] P. Mei, G. F. Pedersen and S. Zhang, "A broadband and FSS-based transmitarray antenna for 5G millimeter-wave applications," IEEE Antennas and Wireless Propagation Letters, vol. 20, no. 1, pp. 103107, 2021. 
[33] S. Shakir, M. Bilal, S. M. Abbas, N. Saleem, Z. Rauf et al., "A compact 8-element 3D UWB diversity antenna system for off device installation," IEEE Access, vol. 9, pp. 44117-44127, 2021.

[34] K. R. Jha, G. Singh and R. Jyoti, "A simple synthesis technique of single square loop frequency selective surface," Progress in Electromagnetics Research B, vol. 45, pp. 165-185, 2012.

[35] G. Bharti, K. R. Jha, G. Singh and R. Jyoti, "Design of angular and polarization stable modified circular ring frequency selective surface for satellite communication system," International Journal of Microwave and Wireless Technologies, vol. 8, no. 6, pp. 899-907, 2016.

[36] Ansys, "3D EM field simulator for RF and wireless design," 2018. [Online]. Available: http://www.ansys.com.

[37] Keysight, "N5242A PNA-X Microwave Network Analyzer, 26.5 GHz," 2018. [Online]. Available: https://www.keysight.com.

[38] Rfglobalnet, "Datasheet: H-1498 series antenna," 2019. [Online]. Available: https://www.rfglobalnet.com /doc/h-1498-series-antenna-0001.

[39] R. Sivasamy, B. Moorthy, M. Kanagasabai, J. V. George, L. Lawrance et al., "Polarization-independent single-layer ultrawideband frequency-selective surface," International Journal of Microwave and Wireless Technologies, vol. 9, no. 1, pp. 93-97, 2017.

[40] D. Sood and C. C. Tripathi, "Polarization insensitive compact wide stopband frequency selective surface," Journal of Microwaves, Optoelectronics and Electromagnetic, vol. 17, no. 1, pp. 53-64, 2018.

[41] G. S. Paul and K. Mandal, "Polarization-insensitive and angularly stable compact ultrawide stop-band frequency selective surface," IEEE Antennas and Wireless Propagation Letters, vol. 18, no. 9, pp. 19171921, 2019.

[42] T. Honget, M. Wang, K. Peng, Q. Zhao and S. Gong, "Compact ultra-wide band frequency selective surface with high selectivity," IEEE Transactions on Antennas and Propagation, vol. 68, no. 7, pp. 57245729, 2020.

[43] B. Hua, X. He and Y. Yang, "Polarisation-independent UWB frequency selective surface based on 2.5D miniaturised hexagonal ring," Electronics Letters, vol. 53, no. 23, pp. 1502-1504, 2017.

[44] S. S. Sampath and R. Sivasamy, "A single-layer UWB frequency selective surface with band-stop response," IEEE Transactions on Electromagnetic Compatibility, vol. 62, no. 1, pp. 276-279, 2020.

[45] W. Yin, H. Zhang, T. Zhong and Q. Chen, "A outstanding miniaturized frequency selective surface based on convoluted interwoven element," Progress in Electromagnetics Research Letters, vol. 69, pp. 133-139, 2017.

[46] S. Habib, G. I. Kiani and M. F. U. Butt, "A convoluted frequency selective surface for wideband communication applications," IEEE Access, vol. 7, pp. 65075-65082, 2019.

[47] R. Dickie, R. Cahill, H. Gamble, V. Fusco, M. Henry et al., "Submillimeter wave frequency selective surface with polarization independent spectral responses," IEEE Transactions on Antennas and Propagation, vol. 57, no. 7, pp. 1985-1994, 2009.

[48] Y. Z. Cheng, W. Withayachumnankul, A. Upadhyay, D. Headland, Y. Nie et al., "Ultrabroadband plasmonic absorber for terahertz waves," Advanced Optical Materials, vol. 3, no. 3, pp. 376-380, 2015.

[49] M. Euler, V. Fusco, R. Cahill and R. Dickie, "325 GHz single layer submillimeter wave FSS based split slot ring linear to circular polarization convertor," IEEE Transactions on Antennas and Propagation, vol. 58, no. 7, pp. 2457-2459, 2010.

[50] Y. Z. Cheng, W. Withayachumnankul, A. Upadhyay, D. Headland, Y. Nie et al., "Ultrabroadband reflective polarization convertor for terahertz waves," Applied Physics Letters, vol. 105, no. 18, pp. 181111, 2014.

[51] N. Behdad, "A second-order band-pass frequency selective surface using nonresonant subwavelength periodic structures," Microwave and Optical Technology Letters, vol. 50, no. 6, pp. 1639-1643, 2008.

[52] A. Ebrahimi, S. Nirantar, W. Withayachumnankul, M. Bhaskaran, S. Sriram et al., "Second-order Terahertz bandpass frequency selective surface with miniaturized elements," IEEE Transactions on Terahertz Science and Technology, vol. 5, no. 5, pp. 761-769, 2015. 